\title{
Self-Reported Exposure to ETS (Environmental Tobacco Smoke), Urinary Cotinine, and Oxidative Stress Parameters in Pregnant Women-The Pilot Study
}

\author{
Lubica Argalasova ${ }^{1, *}$, Ingrid Zitnanova ${ }^{2} \mathbb{0}$, Diana Vondrova ${ }^{1}$, Monika Dvorakova ${ }^{2}$, \\ Lucia Laubertova ${ }^{2}$, Jana Jurkovicova ${ }^{1}$, Juraj Stofko ${ }^{3}$, Michael Weitzman ${ }^{4}$, Iveta Waczulikova ${ }^{5}$ \\ and Martin Simko ${ }^{6}$ \\ 1 Institute of Hygiene, Faculty of Medicine, Comenius University, 81499 Bratislava, Slovakia; \\ diana.vondrova@fmed.uniba.sk (D.V.); jana.jurkovicova@fmed.uniba.sk (J.J.) \\ 2 Institute of Medical Chemistry, Biochemistry and Clinical Biochemistry, Faculty of Medicine, Comenius \\ University, 81499 Bratislava, Slovakia; ingrid.zitnanova@fmed.uniba.sk (I.Z.); \\ monika.dvorakova@fmed.uniba.sk (M.D.); lucia.laubertova@fmed.uniba.sk (L.L.) \\ 3 Institute of Physiotherapy, Balneology and Medical Rehabilitation, University of Ss. Cyril and Methodius in \\ Trnava, 91701 Trnava, Slovakia; juraj.stofko@gmail.com \\ 4 Department of Pediatrics, New York University, New York, NY 10016, USA; \\ Michael.Weitzman@nyulangone.org \\ 5 Division of Biomedical Physics, Department of Nuclear Physics and Biophysics, Faculty of Mathematics, \\ Physics and Informatics, Comenius University, 81499 Bratislava, Slovakia; iveta.waczulikova@fmph.uniba.sk \\ 6 IInd Gynecology and Obstetrics Clinic, Faculty of Medicine, Comenius University, 81499 Bratislava, \\ Slovakia; cyklomartin@gmail.com \\ * Correspondence: lubica.argalasova@fmed.uniba.sk; Tel.: +421-905-209-114
}

Received: 14 March 2019; Accepted: 9 May 2019; Published: 13 May 2019

\begin{abstract}
Background: Exposure to ETS (environmental tobacco smoke) is one of the most toxic environmental exposures. Objective: To investigate the association of ETS with physiological, biochemical, and psychological indicators, as well as with urine antioxidant capacity (AC) and oxidative damage to lipids in a pilot sample of healthy pregnant women. Methods: Exposure to ETS was investigated via a validated questionnaire, and urine cotinine and the marker of oxidative damage to lipids via 8-isoprostane concentrations using an ELISA kit. Urine AC was determined by the spectrophotometric Trolox-equivalent antioxidant capacity (TEAC) method. From a sample of pregnant women ( $n=319$, average age $30.84 \pm 5.09$ years) in 80 , the levels of cotinine and oxidative stress markers were analyzed. Results: Among the 80 pregnant women, 5\% (7.4\% confirmed by cotinine) reported being current smokers and $25 \%$ reported passive smoking in the household $(18.8 \%$ confirmed by cotinine). The Kappa was 0.78 for smokers and 0.22 for ETS-exposed nonsmokers. Pregnant women in the ETS-exposed group had significantly reduced AC compared to both the nonsmoker (ETS-) and the smoker groups $(p<0.05)$. Nonsmokers had significantly lower levels of 8 -isoprostane than smokers $(p<0.01)$ and ETS-exposed nonsmokers $(p<0.05)$. Correlations between urine levels of cotinine and AC were positive in ETS-exposed nonsmokers. Conclusion: A harmful association of active and passive smoking and oxidative stress parameters among pregnant women has been indicated.
\end{abstract}

Keywords: environmental tobacco smoke (ETS); pregnant women; questionnaire; urinary cotinine; oxidative stress parameters 


\section{Introduction}

Exposure to environmental risk factors has a negative impact on health, especially in vulnerable population groups, which include the children, mothers, and pregnant women. Exposure to tobacco smoke is one of the most toxic environmental exposures. Environmental tobacco smoke (ETS) causes over 600,000 deaths per year, with more than a third of all people exposed to the harmful effects of smoke. This corresponds to $1 \%$ of the global burden of diseases worldwide [1]. Around the world, $40 \%$ of children, 33\% of male nonsmokers, and 35\% of female nonsmokers were exposed to ETS in 2004 [2]. According to the Global Adult Tobacco Survey (GATS) (2008-2010), which investigated the prevalence of smoking and passive smoking among women aged 15-49 years in 14 low- and middle-income countries, the prevalence was $0.4 \%$ in Egypt, $30.8 \%$ in Russia, $17.8 \%$ in Mexico, and $72.3 \%$ in Vietnam. In Poland, $26.9 \%$ of women smoke, $45.4 \%$ are exposed to ETS at home, and $24.3 \%$ at work. Slovakia and the Czech Republic did not take part in this survey [3]. According to the WHO, the prevalence of daily adult tobacco smokers in Slovakia in 2016 was $29 \%, 24 \%$ of women and $34 \%$ of men [4].

Diseases arising from smoking are referred to as "smoking-related diseases". These include tumors (lips, throat, esophagus, colon, kidney, bladder, liver, lungs), noncancerous respiratory system diseases, cardiovascular diseases, and many other diseases affecting a wide variety of organ systems [5-10].

Smoking, however, also affects nonsmokers in households and public places where smoking is allowed [11-13]. Nonsmokers are exposed to ETS, a smoke emitted from the burning end of a cigarette or cigar or exhaled by a smoker, which represents a significant health risk [11,12]. Recent studies have demonstrated that ETS is composed of second-hand smoke (SHS) and of third-hand smoke (THS). Third-hand smoke results from residual tobacco smoke pollutants that remain on clothes and hair of smokers and on surfaces, furniture, and dust in indoor environments. Exposure can persist long after smoking has stopped, through the contact with smokers and in indoor spaces in which tobacco is regularly smoked [14,15].

There have been many studies pointing to the harmful effects of passive smoking on exposed groups of adults, children, and pregnant women and their fetuses [13,16-20]. The most serious complications of ETS in pregnancy include spontaneous abortion, preterm birth fetal developmental anomalies, ectopic pregnancy, preterm labor, intrauterine growth retardation of the fetus (intrauterine growth retardation or IUGR), fetal death, and sudden infant death syndrome (SIDS) [11,12,21-24]. Newborns exposed to cigarette smoke during pregnancy have higher rates of neurological disorders with long-term problems in behavioral, emotional, and cognitive functions at later ages [25-27].

Tobacco smoke contains toxic, carcinogenic, and mutagenic chemicals as well as free radicals and reactive oxygen species with potential oxidative damage to biomolecules. The increased production of reactive oxygen species is related to the depletion of antioxidants and the formation of oxidative stress in the organism [28,29]. As a result, lipid oxidation, cell membrane damage, DNA (deoxyribonucleic acid) strand breaks, and the inactivation of some enzymes may occur [30]. Exposure of pregnant women to tobacco smoke causes oxidative stress not only in pregnant women but also in their fetuses [31,32]. Nicotine and its major metabolite cotinine, with a half-life of about 16 to $20 \mathrm{~h}$ (cotinine is the most common biomarker for exposure to cigarette smoke assessed in hair, serum or urine), have high lipid solubility; therefore, they pass rapidly across the placenta into the fetal circulation, with higher levels of cotinine recorded in the fetus than in the mother's plasma [33-37]. The results of several existing studies indicate that smoking prevalence based on self-report closely approximates estimates assessed by cotinine concentrations. The discrepancy among self-reported smokers and nonsmokers may be due to different smoking patterns, including low nicotine dosing or ETS exposure and misreporting regarding smoking status [34-38].

The aim of this study is to assess the degree of ETS exposure and its association with physiological, biochemical, and psychological indicators and with the urine antioxidant capacity and oxidative damage to lipids in a pilot sample of healthy pregnant women. 


\section{Materials and Methods}

Researchers from the Comenius University's Obstetrics and Gynecology (OB/Gyn) Department and Institute of Hygiene in Bratislava, Slovakia distributed surveys to pregnant women in the 36th-41st week of pregnancy being seen for the follow-up at the OB/Gyn Department of the Faculty Hospital and Clinic. This survey has been used previously to investigate environmental, behavioral, and psychological factors in the lives of women [20]. The results of that study found that ETS exposure is an independent risk factor associated with worse physical health of nonsmoking mothers and worse mental health among pregnant women [20]. In the present study, we enlarged the sample of pregnant women and validated the self-reported smoking and ETS exposure by the levels of urinary cotinine and assessed selected oxidative stress parameters in urine specimens. The study was approved by the Ethical Committee of the Faculty of Medicine, Comenius University Bratislava, Slovakia and by the Institutional Review Board of New York University School of Medicine, New York, USA (IRB number: 09-0331).

Exposure to tobacco smoke as well as the analysis of the lifestyle and demographic determinants of passive smoking were assessed by the questionnaire for mothers used in the previous study $[18,20]$. The survey was based on the MEPS (Medical Expenditure Panel Survey) from the USA [18]. The aim of that study was to compare the physical and mental health of non-smoking mothers living in one household with smokers and nonsmokers.

Urine specimens were taken at the routine control into plastic containers that were subsequently frozen at $-20^{\circ} \mathrm{C}$. In the urine samples, levels of cotinine and oxidative stress marker (8-isoprostanes) were analyzed within 3 months of sampling.

\subsection{Investigated Population}

In the present study, 319 (average age $30.84 \pm 5.09$ ) healthy pregnant women without any medical treatment for chronic health conditions were included, and in 80 of them (average age $30.24 \pm 4.92$ years), the levels of cotinine and oxidative stress markers in urine specimens were analyzed from March to June 2018. The study sample was selected from 55,112 deliveries in Slovakia, 7755 deliveries in Bratislava and 2522 deliveries in the IInd Gynecology and Obstetrics Clinic, Faculty of Medicine, Comenius University Bratislava, Slovakia. The planned sample size was 500 healthy pregnant women. In the sample of healthy pregnant women without any medical treatment for chronic conditions who completed the questionnaire $(n=319$; average age $30.8 \pm 5.09), 79.9 \%$ were younger than 35 years old, most of Slovak nationality (94.3\%), 78.2\% were married or in a relationship, 50.5\% graduated from university, $60.6 \%$ were employed, and $57.4 \%$ had children under 18 years of age in their household (Table 1). Because it would not be feasible to perform the biochemical investigations in the whole sample, a simple random sampling was done. The women were included in a list, each coded with the case-specific ID from the institutional electronic database. This list was then numbered in sequential order from one to the total number of the sample. The sampling procedure was performed in the StatsDirect statistical program utilizing this list as a sampling frame. Assuming estimated minimum sample size of 72 women intended for the biochemical analysis, and anticipated dropout rate of $20 \%$, a total of 100 pregnant women were selected and invited to participate in the study. Of these, 92 replied, and 80 agreed and signed a written consent. The levels of cotinine and oxidative stress markers in urine specimens were analyzed from March to June 2018. In this sample of healthy pregnant women $n=80$; average age $30.24 \pm 4.92$ years), $81.20 \%$ were younger than 35 years old, most of Slovak nationality $(93.8 \%), 78.8 \%$ were married or in a relationship, $68.80 \%$ graduated from the college, $66.3 \%$ were employed, and $31.3 \%$ had children under 18 years of age in their household (Table 1 ). 
Table 1. Characteristics of two samples of pregnant women (I $(n=319)$, II $(n=80))$.

\begin{tabular}{|c|c|c|c|c|}
\hline \multirow{2}{*}{$\begin{array}{ll} & \text { Samples } \\
\text { Indicator }{ }^{*} & \\
\end{array}$} & \multicolumn{2}{|c|}{$\mathrm{I}$} & \multicolumn{2}{|c|}{ II } \\
\hline & $n$ & $\%$ & $n$ & $\%$ \\
\hline \multicolumn{5}{|l|}{ Age group } \\
\hline$\leq 35$ & 255 & 79.9 & 65 & 81.2 \\
\hline$>35$ & 64 & 20.1 & 15 & 18.8 \\
\hline \multicolumn{5}{|l|}{ Nationality } \\
\hline Slovak & 299 & 94.3 & 75 & 93.8 \\
\hline other & 18 & 5.7 & 5 & 6.2 \\
\hline \multicolumn{5}{|l|}{ Marital status } \\
\hline married/in a relationship & 248 & 78.2 & 63 & 78.8 \\
\hline single/divorced & 69 & 21.8 & 17 & 21.2 \\
\hline \multicolumn{5}{|l|}{ Number of children under 18} \\
\hline no & 100 & 42.6 & 55 & 68.7 \\
\hline 1 & 107 & 45.5 & 20 & 25.0 \\
\hline 2 & 24 & 10.2 & 5 & 6.3 \\
\hline$\geq 3$ & 4 & 1.7 & 0 & 0.0 \\
\hline \multicolumn{5}{|l|}{ Mother's education } \\
\hline secondary school or lower & 42 & 13.2 & 6 & 7.5 \\
\hline high school graduate & 116 & 36.4 & 19 & 23.7 \\
\hline university degree & 161 & 50.5 & 55 & 68.8 \\
\hline \multicolumn{5}{|l|}{ Employment status of the mother } \\
\hline employed & 191 & 60.6 & 53 & 66.3 \\
\hline unemployed & 124 & 39.4 & 27 & 33.7 \\
\hline \multicolumn{5}{|l|}{ Father's education } \\
\hline secondary school or lower & 63 & 20.0 & 10 & 12.6 \\
\hline high school graduate & 118 & 37.5 & 21 & 26.6 \\
\hline university degree & 134 & 42.5 & 48 & 60.8 \\
\hline \multicolumn{5}{|l|}{ Employment status of the father } \\
\hline employed & 307 & 98.4 & 78 & 98.7 \\
\hline unemployed & 5 & 1.6 & 1 & 1.3 \\
\hline \multicolumn{5}{|l|}{ Household income } \\
\hline$\leq 700 €$ & 62 & 20.1 & 5 & 6.5 \\
\hline$>700 €$ & 246 & 79.9 & 72 & 93.5 \\
\hline \multicolumn{5}{|l|}{ Residence } \\
\hline urban-metropolitan & 229 & 72.2 & 55 & 72.2 \\
\hline rural-non-metropolitan & 88 & 27.8 & 27 & 27.8 \\
\hline \multicolumn{5}{|l|}{ Physical activity } \\
\hline regular & 129 & 41.1 & 40 & 50.6 \\
\hline irregular & 185 & 58.9 & 39 & 49.4 \\
\hline \multicolumn{5}{|l|}{ Healthy lifestyle } \\
\hline & 207 & 65.9 & 54 & 67.5 \\
\hline no/not sure & 107 & 34.1 & 26 & 32.5 \\
\hline \multicolumn{5}{|l|}{ Number of daily meals } \\
\hline$\leq 4$ & 192 & 60.4 & 43 & 54.5 \\
\hline$>4$ & 126 & 39.6 & 36 & 45.5 \\
\hline \multicolumn{5}{|l|}{ Smoking status (self-reported) } \\
\hline nonsmoker & 187 & 58.6 & 59 & 73.8 \\
\hline ex-smoker & 103 & 32.3 & 17 & 21.2 \\
\hline current smoker & 29 & 9.1 & 4 & 5.0 \\
\hline \multicolumn{5}{|l|}{ Exposure to tobacco smoke (self-reported) ${ }^{a}$} \\
\hline not exposed & 156 & 62.2 & 56 & 70.0 \\
\hline exposed & 95 & 37.8 & 20 & 25.0 \\
\hline Smoking status (cotinine objectified-above 2 & & & & \\
\hline no & - & - & 74 & 92.6 \\
\hline yes & - & - & 6 & 7.4 \\
\hline Exposure to tobacco smoke (cotinine objectifie & & & & \\
\hline not exposed & - & - & 59 & 73.8 \\
\hline exposed & - & - & 15 & 18.8 \\
\hline
\end{tabular}

* There are some data missing in each variable category. ${ }^{\text {a }}$ If somebody living in the household is smoking. 


\subsection{Questionnaire}

The "Questionnaire for Mothers" used in our previous studies was administered by a trained person and contained questions on environmental, behavioral, and psychosocial factors in the life of pregnant women $[18,20]$. In addition to questions on personal (age, nationality, marital status, education, employment, children), behavioral (smoking, lifestyle, nutrition), housing (residence), and economic characteristics (household income), it also included questions on mothers' smoking and ETS exposure in the household (smoking spouse or other members of the family, number of cigarettes and number of years of smoking). In the case of a former smoker, there was a question for how many years she/he has not smoked. Former smokers were considered nonsmokers.

\subsection{Chemical Analyses}

\subsubsection{Cotinine}

The level of cotinine was measured in urine samples using a competitive ELISA kit (MyBioSource, San Diego, CA, USA) according to the manufacturer's instructions. Obtained results were expressed in $\mathrm{mg} / \mathrm{mol}$ of creatinine. The assay sensitivity was $1 \mathrm{ng} / \mathrm{mL}$.

Pregnant women were assigned into three groups based on urine cotinine levels: 6 women with cotinine levels above $2 \mathrm{mg} / \mathrm{mol}$ creatinine were included in the smoker group (S), 15 women with cotinine levels between $0.06-2 \mathrm{mg} / \mathrm{mol}$ creatinine into the ETS group (environmental tobacco smoke), and 59 women with cotinine levels below $0.06 \mathrm{mg} / \mathrm{mol}$ creatinine were included into the nonsmoker group (NS).

\subsubsection{Antioxidant Capacity of Urine (TEAC)}

Trolox-equivalent antioxidant capacity (TEAC) decolorization assay (Re et al., 1999) is a decolorization method applicable for both lipophilic and hydrophilic antioxidants. A cation radical 2,2'-azino-bis-3-ethyl benzothiazoline-6-sulfonic acid (ABTS+) is produced by the oxidation of ABTS with potassium persulfate $\left(\mathrm{K}_{2} \mathrm{~S}_{2} \mathrm{O}_{8}\right)$. Added antioxidants reduce the cation radical in a dose- and time-response manner. Decolorization of the cation radical is related to the standard trolox (synthetic, water-soluble form of vitamin E). Results are expressed in $\mathrm{mmol}$ of trolox $/ \mathrm{L} / \mathrm{mol}$ of creatinine.

\subsubsection{8-Isoprostane}

Isoprostane (8-iso prostaglandin F2 $\alpha$ ) levels in urine were determined by the commercial competitive ELISA kit (Cayman Chemical, Ann Arbor, MI, USA) following manufacturer's instructions. Results are expressed in $\mathrm{ng} / \mathrm{mL} / \mathrm{mmol}$ of creatinine. Sensitivity of the assay was $3 \mathrm{pg} / \mathrm{mL}$.

\subsubsection{Creatinine}

Urine creatinine was determined in the certified laboratory (Medirex, a.s., Bratislava, Slovakia).

\subsection{Statistical Analysis}

Descriptive and analytical statistics (categorical data analysis) were employed to identify associations between factors assessed in the questionnaire and self-reported ETS exposure. Kappa statistics, sensitivity, specificity, and correlations were used to determine the extent to which self-reported smoking and exposure to ETS are in agreement with the degree of ETS exposure determined by the levels of urinary cotinine (i.e., to determine the accuracy of self-reported smoking status). Kappa is the percentage of cases in which the two measures are in agreement after accounting for chance agreement [39]. It does not take into account which measure is considered the gold standard. The calculated statistical measures for classification performance of the self-report results included accuracy, sensitivity, specificity, positive predictive value (PPV), and negative predictive value (NPV). Sensitivity is the percentage of true positive (the percentage of respondents who reported being 
smokers or ETS-exposed nonsmokers among those classified as smokers or ETS-exposed nonsmokers based on cotinine concentrations). Specificity is the percentage of true negatives (the percentage of respondents who reported being nonsmokers among those classified as nonsmokers based on cotinine concentrations). The predictive value positive (PVP) and predictive value negative (PVN) are the complements of the percent false positive and percent false negative, respectively [38,40,41]. Statistical package SPSS, version 24 (International Business Machines Corp., New Orchard Road, Armonk, New York, NY, USA) was used for data analysis.

To evaluate the results of chemical analysis, the statistical package SPSS version 18 (SPSS Inc., Chicago, IL, USA) was used. The results are expressed as mean \pm standard deviation (SD) for normally distributed data, or median (lower quartile-upper quartile) for data not normally distributed. One-way analysis of variance followed with post-hoc Tukey test or its nonparametric alternative and Conover-Iman test were used for the comparison between groups of continuous parameters as appropriate.

The association between variables was assessed using Spearman and Pearson correlation coefficients. The latter was calculated for mathematically transformed laboratory variables to improve symmetry of their distribution. Multiple linear regression was used to assess explanatory power of multiple independent variables when predicting the cotinine levels.

We used an alpha level of 0.05 as a significance criterion for all statistical tests.

\section{Results}

In the sample of healthy pregnant women in whom we analyzed the levels of cotinine and oxidative stress markers in urine specimens $(n=80)$, there were $5 \%(4)$ self-reported smokers, $73.8 \%$ (59) self-reported nonsmokers, and $21.2 \%$ (17) ex-smokers. The average number of cigarettes was $5.67 \pm 4.04$ per day, median 5 (2-5); the average duration of smoking was $14.50 \pm 7.78$ years, median 14.50 (9.0-14.5). ETS exposure (somebody living in the household is smoking) was reported in $25 \%$ (20) of nonsmoking respondents. The presence of ETS exposure objectified by cotinine was confirmed in $18.8 \%$ (15) respondents. The average number of cigarettes smoked by the partner/person living in the same household was $10.39 \pm 6.50$ per day, median 10 (5-16.3). The average duration of smoking was $13.43 \pm 5.90$ years (Table 1 ). There were $5 \%$ (4) self-reported current smokers and $7.4 \%(6)$ current smokers as assessed by the level of cotinine in the urine sample and $25 \%$ (20) self-reported ETS-exposed nonsmokers and 18.8\% (15) ETS-exposed nonsmokers confirmed by the level of cotinine in the urine sample.

ETS-exposed pregnant women are younger, more of other than Slovak nationalities, are less educated and have fewer children than ETS non-exposed pregnant women. They are from lower-income families and live mostly in rural areas. They eat and live less healthily than women not exposed to ETS. Due to the small sample size, these findings are not statistically significant (Table 2).

The sensitivity for self-reported smoking status was $66.7 \%$, specificity $100 \%$, positive predictive value $100 \%$, and negative predictive value $95.8 \%$. Kappa was 0.78 , indicating substantial agreement [42] or excellent agreement [39]. The sensitivity for self-reported ETS exposure was $46.7 \%$, specificity $78 \%$, positive predictive value $35 \%$, negative predictive value $85.2 \%$. Kappa was indicating fair agreement [42] or poor agreement [39]. The agreement for self-reported ETS exposure was better for younger women ( $\leq 35$ years) and with lower education, reaching moderate or fair to good agreement $($ Kappa $=0.44)($ Table 3) $[39,42]$. 
Table 2. Relation between demographic factors and mother's exposure to tobacco smoke (cotinine objectified-0.06-2 mg/mol creatinine) $n=80$.

\begin{tabular}{|c|c|c|c|c|}
\hline \multirow[t]{2}{*}{ Indicator * } & \multicolumn{2}{|c|}{ ETS- } & \multicolumn{2}{|c|}{ ETS+ } \\
\hline & $n$ & $\%$ & $n$ & $\%$ \\
\hline \multicolumn{5}{|l|}{ Age group } \\
\hline$\leq 35$ & 10 & 16.95 & 4 & 26.67 \\
\hline$>35$ & 49 & 83.05 & 11 & 73.33 \\
\hline \multicolumn{5}{|l|}{ Nationality } \\
\hline Slovak & 57 & 96.61 & 14 & 93.33 \\
\hline other & 2 & 3.39 & 1 & 6.67 \\
\hline \multicolumn{5}{|l|}{ Marital status } \\
\hline married/in relationship & 41 & 69.50 & 11 & 73.30 \\
\hline single/divorced & 18 & 30.50 & 4 & 26.70 \\
\hline \multicolumn{4}{|l|}{ Number of children in household } & 80.00 \\
\hline $1-2$ & 19 & 32.20 & 3 & 20.00 \\
\hline$\geq 3$ & 0 & 0.00 & 0 & 0.00 \\
\hline \multicolumn{5}{|l|}{ Mother's education } \\
\hline secondary school or lower & 0 & 0.00 & 2 & 13.33 \\
\hline high school graduate & 15 & 25.42 & 4 & 26.67 \\
\hline university degree & 44 & 74.58 & 9 & 60.00 \\
\hline \multicolumn{5}{|l|}{ Employment status of mother } \\
\hline employed & 39 & 66.10 & 11 & 73.33 \\
\hline unemployed & 20 & 33.90 & 4 & 26.67 \\
\hline \multicolumn{5}{|l|}{ Father's education } \\
\hline secondary school or lower & 5 & 8.47 & 3 & 21.43 \\
\hline high school graduate & 16 & 27.12 & 3 & 21.43 \\
\hline college graduate and more & 38 & 64.61 & 8 & 57.14 \\
\hline \multicolumn{5}{|l|}{ Employment status of father } \\
\hline $\begin{array}{l}\text { employed } \\
\text { unemployed }\end{array}$ & 59 & 100.00 & 14 & 100.00 \\
\hline \multicolumn{5}{|l|}{ Household income } \\
\hline$\leq 700 €$ & 2 & 3.4 & 1 & 7.10 \\
\hline$>700 €$ & 56 & 96.6 & 13 & 92.90 \\
\hline \multicolumn{5}{|l|}{ Urban/rural residence } \\
\hline urban-metropolitan area & 44 & 74.58 & 10 & 66.67 \\
\hline rural-nonmetropolitan area & 15 & 25.42 & 5 & 33.33 \\
\hline \multicolumn{4}{|l|}{ Physical activity } & 26.67 \\
\hline irregular & 23 & 39.66 & 11 & 73.33 \\
\hline \multicolumn{5}{|l|}{ Number of daily meals } \\
\hline$\leq 4$ & 29 & 49.15 & 11 & 78.57 \\
\hline$>4$ & 30 & 50.85 & 3 & 21.43 \\
\hline \multicolumn{5}{|l|}{ Healthy lifestyle } \\
\hline & 43 & 72.88 & 9 & 60.00 \\
\hline no/not sure & 16 & 27.12 & 6 & 40.00 \\
\hline
\end{tabular}

ETS+ exposed to tobacco smoke; ETS- not exposed to tobacco smoke; ${ }^{*}$ There are some data missing in each variable category.

Table 3. Measures of agreement to determine the accuracy of self-reported smoking status and exposure to ETS with the urine cotinine analysis in the sample of pregnant women $(n=80)$.

\begin{tabular}{ccccc}
\hline & \multicolumn{3}{c}{ Smoking Status } \\
\cline { 2 - 5 } Measures of Agreement & $\begin{array}{c}\text { Nonsmoker vs. } \\
\text { Current Smoker }\end{array}$ & Total & $\begin{array}{c}\text { Younger Age } \\
\text { Group ( } \leq \text { 35 Years) }\end{array}$ & Lower Education \\
\cline { 2 - 5 } & Total & 0.22 & 0.30 & 0.45 \\
Kappa & 0.78 & $46.7 \%$ & $54.6 \%$ & $66.7 \%$ \\
Sensitivity & $66.7 \%$ & $78.0 \%$ & $79.6 \%$ & $80.0 \%$ \\
Specificity & $100.0 \%$ & $35.0 \%$ & $37.5 \%$ & $57.1 \%$ \\
Negitive predictive value & $100.0 \%$ & $85.2 \%$ & $88.6 \%$ & $85.7 \%$ \\
Diagnostic accuracy & $95.8 \%$ & $71.6 \%$ & $75.0 \%$ & $76.2 \%$ \\
\hline
\end{tabular}

ETS+ exposed to tobacco smoke; ETS- not exposed to tobacco smoke. 
The median value of cotinine in ETS-exposed pregnant women by self-report was $0.22(0.129-0.338)$ and in currently smoking pregnant women 253.19 (181.82-498.31) mg/mol creatinine. Pregnant women in the ETS+ group had significantly reduced urine antioxidant capacity (TEAC) compared to both the non-smoker (ETS-) and the smoker groups (Tables 4 and 5). There was no significant difference in urine antioxidant capacity between the nonsmokers and the smokers. The marker of oxidative damage to lipids-8-isoprostanes were significantly increased in the ETS+ and the smoker group compared to the nonsmoker group. The 8-isoprostane levels were the highest in the smoker's group; however, there was no statistically significant difference between ETS+ and smokers' groups.

Table 4. Cotinine levels, Trolox-equivalent antioxidant capacity (TEAC), and levels of 8-isoprostanes.

\begin{tabular}{lccc}
\hline Actual Smoking Status & $\begin{array}{c}\text { Cotinine } \\
\mathbf{m g} / \text { mol Creatinine }\end{array}$ & $\begin{array}{c}\text { TEAC } \\
\text { mmol trolox/L/mol Creatinine }\end{array}$ & $\begin{array}{c}\text { 8-Isoprostanes } \\
\text { ng/mL/mmol Creatinine }\end{array}$ \\
\hline ETS $-(n=59)$ & $0.00 \pm 0.00$ & $1.2 \pm 0.4$ & $143.6(73.91-197.54)$ \\
ETS $+(n=15)$ & $0.22(0.129-0.338)$ & $0.91 \pm 0.28$ & $238.41(112.26-411.88)$ \\
current smoker $(n=6)$ & $253.19(181.82-498.31)$ & $1.3 \pm 0.43$ & $293.74(250.17-377.51)$ \\
\hline
\end{tabular}

ETS+ exposed to tobacco smoke; ETS- not exposed to tobacco smoke (cotinine validated-0.06-2 mg/mol creatinine for ETS, above $2 \mathrm{mg} / \mathrm{mol}$ creatinine for current smokers). Results are expressed as the mean \pm SD or the median (lower quartile-upper quartile).

Table 5. Statistical significance ( $p$-value) of TEAC and levels of 8-isoprostanes.

\begin{tabular}{lcc}
\hline Smoking Status & TEAC & 8-Isoprostanes \\
\hline ETS+ vs. ETS- & $0.0038^{*}$ & $0.0384^{*}$ \\
ETS+ vs. current smoker & 0.0563 & 0.2614 \\
current smoker vs. ETS- & 0.8429 & $0.0098^{*}$ \\
\hline
\end{tabular}

ETS+ exposed to tobacco smoke; ETS- not exposed to tobacco smoke (cotinine validated-0.06-2 mg/mol creatinine for ETS, above $2 \mathrm{mg} / \mathrm{mol}$ creatinine for current smokers); * significant at $p<0.05$.

Significant positive correlation between urine cotinine levels and urine antioxidant capacity (TEAC) in the ETS-exposed group was found (Table 6).

Table 6. Correlations between cotinine levels in urine and oxidative stress parameters.

\begin{tabular}{ccc}
\hline Antioxidant Parameters & Rho & $p$-Value \\
\hline ETS- & & \\
TEAC & -0.2036 & 0.0642 \\
isoprostanes & 0.0676 & 0.3097 \\
\hline ETS+ & & \\
TEAC & 0.7607 & $0.0007^{*}$ \\
8-isoprostanes & -0.2179 & 0.2171 \\
\hline Current smoker & & \\
TEAC & -0.0857 & 0.4014 \\
8-isoprostanes & -0.5429 & 0.1208 \\
\hline
\end{tabular}

ETS+ exposed to tobacco smoke; ETS- not exposed to tobacco smoke (cotinine objectified-0.06-2 mg/mol creatinine for ETS, above $2 \mathrm{mg} / \mathrm{mol}$ creatinine for current smokers); Rho-Spearman's rank correlation coefficient; * significant at $p<0.05$.

To investigate the extent to which TEAC, 8-isoprostanes, and questionnaire classification uniquely correlate with cotinine values, multiple linear regression on normalized laboratory variables was performed. Since the stratified correlation analysis suggested some kind of interaction between laboratory values and smoking status (Table 6), interaction terms were also included (Table 7-above). The model confirmed our expectation of high explanatory value of self-reported smoking. Interpretation of self-reported exposure to ETS should be taken with caution due to suspected interaction between 
the smoking status and TEAC pointing to the possible nonlinear relationship between the variables. Explanatory power of self-reported exposure to ETS could be improved by measuring TEAC $(p=0.0994)$.

Table 7. Multiple linear regression modeling of transformed cotinine levels.

\begin{tabular}{lccc}
\hline \multicolumn{1}{c}{ Parameter } & Regression Coef. & Partial Correlation Coef. & $p$-Value \\
\hline Intercept & -2.3265 & & 0.0048 \\
Current smoker_questionnaire (Q) & 7.3793 & 0.8178 & $<0.0001$ \\
ETS+_questionnaire (Q) & 0.0712 & 0.0272 & 0.8180 \\
ln TEAC (mol Trolox/mol Creatinine) & 2.2096 & 0.4654 & $<0.0001$ \\
ln TEAC * Current smoker_Q & -2.8214 & -0.1939 & 0.0979 \\
ln TEAC * ETS+_Q & -1.5087 & -0.1930 & 0.0994 \\
Ln (Isoprostanes pg/mL/mmol Creatinine) & 0.1606 & 0.1206 & 0.3062 \\
\hline
\end{tabular}

Analysis of variance from regression: $\mathrm{F}=28.97 ; p<0.0001$; multiple correlation coefficient $\mathrm{R}=0.8409 ; \mathrm{R}_{\mathrm{adj}}{ }^{2}=68.27 \%$.

* interactions between the self-reported smoking status, ETS exposure and TEAC; Coef.: coefficient.

\section{Discussion}

The results of our previous studies show that ETS is one of the most important factors associated with the physical and mental health of exposed, nonsmoking partners [20]. That study, using a nationally representative sample from the years 2000 to 2004 in the USA [18], showed a negative relationship between living with smokers and the physical and mental health of nonsmoking mothers with children [18]. The limitation of our previous studies was the fact that the smoking status was ascertained exclusively via self-reporting. Since there is considerable public awareness about the effects of cigarette smoking and ETS exposure, participants might be motivated to underreport their smoking status, although there is evidence in some studies to show that self-report is an accurate way to measure smoking behaviors [38,43-47].

The strength of the present study is the determination of the accuracy of self-reported smoking and ETS exposure status by urinary cotinine and investigation of the association of ETS and the urine antioxidant capacity (AC) and oxidative damage to lipids. Active smoking of pregnant women or ETS exposure results in several problems, such as intrauterine growth retardation, an increased risk of spontaneous abortion, reduction of pulmonary function in healthy neonates or a higher risk of sudden infant death syndrome [22]. One of the possible mechanisms explaining these effects is the presence of the smoke-induced oxidative stress leading to the oxidative damage to molecules and to the inflammatory response [48]. Cigarette smoke contains a large number of free radicals as well as metals such as copper, mercury, and zinc [49], which may catalyze the production of very reactive hydroxyl radicals by the Fenton reaction [50]. Smoking may increase oxidative stress not only through the generation of free radicals but also through the depletion of the antioxidant systems protecting the organism against deleterious effects of oxygen radicals.

In our study, we examined the association of ETS exposure and active smoking on the oxidative damage to lipids and on the antioxidant capacity of urine in pregnant women. In the past decades, numerous studies have shown that 8-isoprostanes are extremely accurate markers of lipid peroxidation [51-54]. 8-isoprostanes are compounds produced by the non-enzymatic oxidation of arachidonic acid. We have found that pregnant women exposed to ETS had significantly higher oxidative damage to lipids and significantly lower urine antioxidant capacity than nonsmokers not exposed to ETS. These results indicate that ETS-exposed pregnant women are under increased oxidative stress, which is in accord with other studies [55-57] Smoking pregnant women had 8-isoprostanes levels similar to the ETS group and antioxidant capacity similar to the nonsmokers. In the smoker group, compared to the ETS and the nonsmoker groups, women are exposed to a higher load of oxidants, which may stimulate compensatory mechanisms leading to an increased antioxidant capacity. Results of other studies on oxidative stress of smoking pregnant women are mixed. Similar results were reported also in plasma and saliva by other studies [28,32,58]. By contrast, Fayol et al. (2005) detected higher plasma antioxidant activity in ETS-exposed pregnant women than in controls [59]. 
In addition, we observed a strong, significant, positive correlation between urine antioxidant capacity and urine cotinine levels only in the ETS+ group. ETS-exposed pregnant women might be sensitive to tobacco smoke and able to correspondingly stimulate their antioxidant system. However, in the smoker group, this correlation was nonsignificantly negative, which might be the consequence of the higher use of antioxidant compounds by the fetus in order to counteract the increased oxidative burden in active smokers.

ETS exposure or active smoking of pregnant women can have negative effects on their fetuses. There are several reports providing evidence of increased oxidative damage to lipids, DNA, and proteins in the blood of such neonates (Kurt et al., 2016) as well as correlations between oxidative stress parameters of pregnant women and their neonates [60]. Increased oxidative damage to important biomolecules in the fetus caused by cigarette smoke has been implicated in the etiopathogenesis of over 100 disorders [59]. Increased consumption of dietary antioxidants might be a potential therapeutic means against increased oxidative stress in ETS-exposed pregnant women and actively smoking pregnant women.

The validity of self-reported smoking in population surveys remains an important question [44]. In our study, self-report was in strong agreement with validation by cotinine assessment ( $78 \%$ agreement). Sensitivity was $66.7 \%$ and specificity $100 \%$. There are studies with higher sensitivities using larger samples $[38,44,61,62]$. Self-reported nonsmokers who are smokers based on biochemical measurements do not admit their true smoking status [43]. In studies comparing questionnaire responses on smoking status with cotinine measurements, the estimated misclassification rates (self-reported nonsmokers with cotinine levels indicating current smoking) ranged from $0.9 \%$ to $9.8 \%[43,44,62,63]$. In our study, the misclassification rate for pregnant smokers was 3.9\%.

The agreement for ETS-exposed pregnant nonsmokers is much lower (22\% agreement, $46.7 \%$ sensitivity and $78 \%$ specificity). The misclassification rate for underreported ETS exposure was $10.81 \%$, but for overreported ETS exposure $17.57 \%$. Older and more educated respondents are more likely to overestimate their ETS exposure (Table 4). The pregnancy itself may also play a role in overestimation of ETS exposure. In the analysis of the lifestyle and demographic determinants of passive smoking, ETS-exposed pregnant women are younger, more of other than Slovak nationalities, are less educated, and have fewer children. They are from lower-income families and live mostly in rural areas. They eat and live less healthily than women not exposed to ETS. These results are similar to those of other studies, but due to a small sample size, we cannot state this with a statistical significance $[18,20]$.

The main conclusion of several studies on large population samples is that the validity of self-reported smoking is high in population-based studies, and the use of cotinine measurements for validation purposes may not be necessary $[38,43,44]$. Further research may assess the optimal cutoff for validating smoking status among specific groups, such as pregnant women. The effects of gender, social conditions, and pregnancy status on the metabolism of nicotine and on smoking behaviors they should be taken into account. Our pilot study adds a new approach, analyzing urinary cotinine together with selected oxidative stress parameters and following their interactions. According to the results reported in this paper, the explanatory power of self-reported exposure to ETS could be improved by measuring TEAC $(p=0.0994)$.

Findings of several studies suggest that most pregnant women disclose their smoking and ETS exposure as well. Universal urinary cotinine screening of pregnant women could help to monitor high risk for adverse pregnancy outcomes [64-66]. Pregnancy smoking might fluctuate, as women try repeatedly to quit or cut down. In this case, cotinine measures may be of limited use for validation. They inform only about a recent exposure, vary with individual smoking status, and depend on the time since the last cigarette smoked [61]. More than $15 \%$ of rural pregnant women in China with actual exposure to ETS might not perceive themselves as passive smokers in prenatal care, especially in the first trimester [47].

Limitations of our study are the small sample size and the cross-sectional design. In our study, we did not use the medical outcomes short form-12 (SF-12) to assess the mental and physical health of 
pregnant women because pregnancy could influence the mental health (MCS) and physical health PCS scores $[20,47,67]$. The strength of our study is the separation of current smokers, ETS-exposed and ETS non-exposed nonsmokers and the investigation of the harmful effects of active and passive smoking on detected oxidative stress parameters.

\section{Conclusions}

Data from our study show that maternal cigarette smoking and ETS exposure during pregnancy may compromise the balance between reactive oxygen species and antioxidant defense and might cause potent oxidative stress with its negative consequences in pregnancy.

Combining the maternal self-report of smoking with the level of urine cotinine concentration could improve the precision of assessment of exposure to tobacco smoke. Urine testing for cotinine may be useful in reducing the nondisclosure surrounding prenatal tobacco use. This screening could be a valuable tool for counseling to help pregnant women in tobacco smoking cessation. The presented results might be used in clinical practice and in campaigns for smoke-free environments and in the promotion of community-based smoke-free programs. Furthermore, they represent an important argument for intervention in families. A complete smoking ban at home should be considered to avoid potential adverse effects on pregnancy outcomes due to ETS.

Author Contributions: L.A., I.Z., M.S., and M.W. conceived and designed the project; L.A., I.Z., and M.S. wrote the manuscript; L.A., D.V., and I.Z. analyzed the data; I.Z., M.D., and L.L. did the chemical laboratory analysis; J.J. and M.W. provided critical revision of the manuscript; M.S., I.Z., L.A., and J.J. performed literature search and drafted sections of the manuscript; J.S. was responsible for funding acquisition and project administration; M.W. provided critical revision of the manuscript and did the language, style, and spell check; I.W. did re-analysis of the collected data in order to help answer questions and concerns raised by reviewers. All authors have approved the submitted version.

Funding: This manuscript was partially supported by the grant Y.A.B.S. (Youth and Parents Behavioral Survey in Slovakia) O-15-101-/0001-00, by the ESFOPV project, MPH study program development at Comenius University in Bratislava in English language (Master of Public Health) ITMS code of the project: 261402300093.

Acknowledgments: We thank the staff of IInd Gynecology and Obstetrics Clinic, Medical Faculty, Comenius University Bratislava, Slovakia for helping us with the performance of the project.

Conflicts of Interest: The authors declare no conflict of interest.

\section{References}

1. World Health Organization. Global Health Observatory Data. Second-Hand Smoke. Available online: http://www.who.int/gho/phe/secondhand_smoke/en/ (accessed on 22 January 2019).

2. Oberg, M.; Jaakkola, M.S.; Woodward, A.; Peruga, A.; Pruess-Ustuen, A. Worldwide burden of disease from exposure to second-hand smoke: A retrospective analysis of data from 192 countries. Lancet 2011, 377, 139-146. [CrossRef]

3. Centers for Disease Control and Prevention. Current tobacco use and secondhand smoke exposure among women of reproductive age-14 countries, 2008-2010. MMWR Morb. Mortal. Wkly. Rep. 2012, 2, 877-882.

4. World Health Organization. WHO Report on the Global Tobacco Epidemic, 2017: Monitoring Tobacco Use and Prevention Policies; WHO: Geneva, Switzerland, 2017.

5. Ezzati, M.; Lopez, A.D. Estimates of global mortality attribu to smoking in 2000. Lancet 2003, 362, 847-852. [CrossRef]

6. Teo, K.K.; Ounpuu, S.; Hawken, S.; Pandey, M.R.; Valentin, V.; Hunt, D.; Diaz, R.; Rashed, W.; Freeman, R.; Jiang, L.; et al. Tobacco use and risk of myocardial infarction in 52 countries in the INTERHEART study: A case-control study. Lancet 2006, 368, 647-658. [CrossRef]

7. Jacob, V.; Vellappally, S.; Smejkalova, J. The influence of cigarette smoking on various aspects of periodontal health. Acta Med. 2007, 50, 3-5. [CrossRef]

8. Jang, A.-Y.; Lee, J.-K.; Shin, J.-Y.; Lee, H.-Y. Association between Smoking and Periodontal Disease in Korean Adults: The Fifth Korea National Health and Nutrition Examination Survey (2010 and 2012). Korean J. Fam. Med. 2016, 37, 117-122. [CrossRef] 
9. Kasajova, P.; Holubekova, V.; Mendelova, A.; Lasabova, Z.; Zubor, P.; Kudela, E.; Biskupska-Bodova, K.; Danko, J. Active cigarette smoking and the risk of breast cancer at the level of N-acetyltransferase 2 (NAT2) gene polymorphisms. Tumor Biol. 2016, 37, 7929-7937. [CrossRef]

10. Santoro, A.; Prinzi, G.; Lamonaca, P.; Cardaci, V.; Fini, M.; Russo, P. Tobacco Smoking: Risk to Develop Addiction, Chronic Obstructive Pulmonary Disease, and Lung Cancer. Recent Pat. Anticancer Drug Discov. 2019, 14, 39-52. [CrossRef]

11. U.S. Department of Health and Human Services. The Health Consequences of Smoking—50 Years of Progress: A Report of the Surgeon General; Department of Health and Human Services; Centers for Disease Control and Prevention; National Center for Chronic Disease Prevention and Health Promotion; Office on Smoking and Health: Atlanta, GA, USA, 2014.

12. U.S. Department of Health and Human Services. The Health Consequences of Involuntary Exposure to Tobacco Smoke: A Report of the Surgeon General; U.S. Department of Health and Human Services; Centers for Disease Control and Prevention; Coordinating Center for Health Promotion; National Center for Chronic Disease Prevention and Health Promotion; Office on Smoking and Health: Atlanta, GA, USA, 2006.

13. Besaratinia, A.; Pfeifer, G.P. Second-hand smoke and human lung cancer. Lancet Oncol. 2008, 9, 657-666. [CrossRef]

14. Protano, C.; Vitali, M. The New Danger of Thirdhand Smoke: Why Passive Smoking Does Not Stop at Secondhand Smoke. Environ. Health Perspect. 2011, 119, a422. [CrossRef] [PubMed]

15. Matt, G.E.; Quintana, P.J.E.; Destaillats, H.; Gundel, L.A.; Sleiman, M.; Singer, B.C.; Jacob, P.; Benowitz, N.; Winickoff, J.P.; Rehan, V.; et al. Thirdhand tobacco smoke: Emerging evidence and arguments for a multidisciplinary research agenda. Environ. Health Perspect. 2011, 119, 1218-1226. [CrossRef] [PubMed]

16. Forastiere, F.; Mallone, S.; Lo Presti, E.; Baldacci, S.; Pistelli, F.; Simoni, M.; Pedreschi, M.; Pistelli, R.; Corbo, G.; Rapiti, E.; et al. Characteristics of nonsmoking women exposed to spouses who smoke: Epidemiologic study on environment and health in women from four Italian areas. Environ. Health Perspect. 2000, 108, 1171-1177. [CrossRef]

17. Wu, F.Y.; Wu, H.D.I.; Yang, H.L.; Kuo, H.W.; Ying, J.C.; Lin, C.J.; Yang, C.C.; Lin, L.Y.; Chiu, T.H.; Lai, J.S. Associations among genetic susceptibility, DNA damage, and pregnancy outcomes of expectant mothers exposed to environmental tobacco smoke. Sci. Total Environ. 2008, 404, 218-219. [CrossRef]

18. Sobotova, L.; Liu, Y.H.; Burakoff, A.; Sevcikova, L.; Weitzman, M. Household Exposure to Secondhand Smoke is Associated with Decreased Physical and Mental Health of Mothers in the USA. Matern. Child Health J. 2011, 15, 128-137. [CrossRef] [PubMed]

19. Zhou, S.; Rosenthal, D.G.; Sherman, S.; Zelikoff, J.; Gordon, T.; Weitzman, M. Physical, behavioral, and cognitive effects of prenatal tobacco and postnatal secondhand smoke exposure. Curr. Probl. Pediatr. Adolesc. Health Care 2014, 44, 219-241. [CrossRef]

20. Argalasova, L.; Sevcikova, L.; Jurkovicova, J.; Babjakova, J.; Janekova, E.; Totka, A.; Simko, M.; Weitzman, M. Determinants of ETS exposure in a sample of Slovak pregnant women. Rev. Environ. Health 2017, 32, 201-205. [CrossRef]

21. Hrubá, D.; Kachlík, P. The influence of maternal active and passive smoking during pregnancy on birth weight in newborns. Cent. Eur. J. Public Health 2000, 8, 249-252.

22. DiFranza, J.; Aligne, C.; Weitzman, M. Prenatal and postnatal environmental tobacco smoke exposure and children's health. Pediatrics 2004, 113, 1007-1015. [PubMed]

23. Polanska, K.; Hanke, W.; Ronchetti, R.; van den Hazel, P.; Zuurbier, M.; Koppe, J.; Bartonova, A. Environmental tobacco smoke exposure and children's health. Acta Paediatr. 2006, 95, 86-92. [CrossRef] [PubMed]

24. Cui, H.; Gong, T.-T.; Liu, C.-X.; Wu, Q.-J. Associations between Passive Maternal Smoking during Pregnancy and Preterm Birth: Evidence from a Meta-Analysis of Observational Studies. PLoS ONE 2016, 11, e0147848. [CrossRef] [PubMed]

25. Button, T.; Maughan, B.; McGuffin, P. The relationship of maternal smoking to psychological problems in the offspring. Early Hum. Dev. 2007, 83, 727-732. [CrossRef]

26. Kukla, L.; Hrubá, D.; Tyrlík, M. Maternal smoking during pregnancy, behavioral problems and school performances of their school-aged children. Cent. Eur. J. Public Health 2008, 16, 71-76. [CrossRef]

27. Bublitz, M.H.; Stroud, L.R. Maternal smoking during pregnancy and offspring brain structure and function: Review and agenda for future research. Nicotine Tob. Res. 2012, 14, 388-397. [CrossRef] 
28. Aycicek, A.; Erel, O.; Kocyigit, A. Decreased total antioxidant capacity and increased oxidative stress in passive smoker infants and their mothers. Pediatr. Int. 2005, 47, 635-639. [CrossRef]

29. Aycicek, A.; Erel, O.; Kocyigit, A. Increased oxidative stress in infants exposed to passive smoking. Eur. J. Pediatr. 2005, 164, 775-778. [CrossRef]

30. Seet, R.; Lee, C.; Loke, W.; Huang, S.; Huang, H.; Looi, W.; Chew, E.; Quek, A.; Lim, E.; Halliwell, B. Biomarkers of oxidative damage in cigarette smokers: Which biomarkers might reflect acute versus chronic oxidative stress? Free Radic. Biol. Med. 2011, 50, 1787-1793. [CrossRef]

31. Aycicek, A. Tobacco Smoking and Oxidative Stress in Pregnancy. In Perinatal and Prenatal Disorders, Oxidative Stress in Applied Basic Research and Clinical Practice; Dennery, P.A., Buonocore, G., Saugstad, O.D., Eds.; Humana Press: New York, NY, USA, 2014. [CrossRef]

32. Chelchowska, M.; Ambroszkiewicz, J.; Gajewska, J.; Laskowska-Klita, T.; Leibschang, J. The effect of tobacco smoking during pregnancy on plasma oxidant and antioxidant status in mother and newborn. Eur. J. Obstet. Gynecol. Reprod. Biol. 2011, 155, 132-136. [CrossRef]

33. Sastry, B.V.; Chance, M.B.; Hemontolor, M.E.; Goddijn-Wessel, T.A. Formation and retention of cotinine during placental transfer of nicotine in human placental cotyledon. Pharmacology 1998, 57, 104-116. [CrossRef]

34. Al-Delaimy, W.K.; Crane, J.; Woodward, A. Is the hair nicotine level a more accurate biomarker of environmental tobacco smoke exposure than urine cotinine? J. Epidemiol. Community Health 2002, 56, 66-71. [CrossRef]

35. Behera, D.; Uppal, R.; Majumdar, S. Urinary levels of nicotine \& cotinine in tobacco users. Indian J. Med. Res. 2003, 118, 129-133.

36. Wipfli, H.; Avila-Tang, E.; Navas-Acien, A.; Kim, S.; Onicescu, G.; Yuan, J.; Breysse, P.; Samet, J.M. Secondhand Smoke Exposure Among Women and Children: Evidence From 31 Countries. Am. J. Public Health 2008, 98, 672-679. [CrossRef]

37. Berlin, I.; Heilbronner, C.; Georgieu, S.; Meier, C.; Spreux-Varoquaux, O. Newborns cord blood plasma cotinine concentrations are similar to that of their delivering smokers mothers. Drug Alcohol Depend. 2010, 107, 250-252. [CrossRef]

38. Wong, S.L.; Shields, M.; Leatherdale, S.; Malaison, E.; Hammond, D. Assessment of validity of self-reported smoking status. Health Rep. 2012, 23, 47-53.

39. Fleiss, J.L. Statistical Methods for Rates and Proportions, 2nd ed.; John Wiley: New York, NY, USA, 1981; pp. 38-46.

40. Hennekens, C.H.; Buring, J.E. Epidemiology in Medicine, 1st ed.; Little, Brown and Company: Boston, MA, USA, 1987; pp. 327-335.

41. Rothmann, K.J.; Greenland, S.; Lash, T.L. Modern Epidemiology, 3rd ed.; Lippincott Williams \& Wilkins: Philadelphia, PA, USA, 2008; pp. 642-646.

42. Landis, J.R.; Koch, G.G. The measurement of observer agreement for categorical data. Biometrics 1977, 33, 159-174. [CrossRef]

43. Rebagliato, M. Validation of self-reported smoking. J. Epidemiol. Community Health 2002, 56, $163-164$. [CrossRef]

44. Vartiainen, E.; Seppälä, T.; Lillsunde, P.; Puska, P. Validation of self-reported smoking by serum cotinine measurement in a community-based study. J. Epidemiol. Community Health 2002, 56, 167-170. [CrossRef]

45. de Chazeron, I.; Llorca, P.M.; Ughetto, S.; Coudore, F.; Boussiron, D.; Perriot, J.; Vendittelli, F.; Sapin, V.; Lemery, D. Occult maternal exposure to environmental tobacco smoke exposure. Tob. Control 2007, 16, 64-65. [CrossRef]

46. Paek, Y.J.; Kang, J.B.; Myung, S.K.; Lee, D.H.; Seong, M.W.; Seo, H.G.; Cho, J.J.; Song, H.J.; Park, K.H.; Kim, C.H.; et al. Self-reported exposure to second-hand smoke and positive urinary cotinine in pregnant nonsmokers. Yonsei Med. J. 2009, 50, 345-351. [CrossRef]

47. Xiao, X.; Li, Y.; Song, X.; Xu, Q.; Yang, S.; Wu, J.; Seto, E. Discrepancy between Self-Reported and Urine Cotinine-Verified Environmental Tobacco Smoke Exposure among Rural Pregnant Women in China. Int. J. Environ. Res. Public Health 2018, 15, 1499. [CrossRef]

48. Biri, A.; Bozkurt, N.; Turp, A.; Kavutcu, M.; Himmetoglu, O.; Durak, I. Role of oxidative stress in intrauterine growth restriction. Gynecol. Obstet. Investig. 2007, 64, 187-192. [CrossRef]

49. Pappas, R.S. Toxic elements in tobacco and in cigarette smoke: Inflammation and sensitization. Metallomics 2011, 11, 1181-1198. [CrossRef] 
50. Kanti Das, T.; Wati, M.R.; Fatima-Shad, K.J.A.N. Oxidative Stress Gated by Fenton and Haber Weiss Reactions and its Association with Alzheimer's disease. Arch. Neurosci. 2015, 2, e20078. [CrossRef]

51. Janicka, M.; Kot-Wasik, A.; Kot, J.; Namieśnik, J. Isoprostanes-Biomarkers of Lipid Peroxidation: Their Utility in Evaluating Oxidative Stress and Analysis. Int. J. Mol. Sci. 2010, 11, 4631-4659. [CrossRef]

52. Fam, S.S.; Morrow, J.D. The isoprostanes: Unique products of arachidonic acid oxidation-A review. Curr. Med. Chem. 2003, 10, 1723-1740. [CrossRef]

53. Cracowski, J.L.; Durand, T.; Bessard, G. Isoprostanes as a biomarker of lipid peroxidation in humans: Physiology, pharmacology and clinical implications. Trends Pharmacol. Sci. 2002, 23, 360-366. [CrossRef]

54. Lawson, J.A.; Rokach, J.; FitzGerald, G.A. Isoprostanes: Formation, analysis and use as indices of lipid peroxidation in vivo. J. Biol. Chem. 1999, 274, 24441-24444. [CrossRef]

55. Park, E.Y.; Hong, Y.C.; Lee, K.H.; Im, M.W.; Ha, E.; Kim, Y.J.; Ha, M. Maternal exposure to environmental tobacco smoke, GSTM1/T1 polymorphisms and oxidative stress. Reprod. Toxicol. 2008, 26, 197-202. [CrossRef]

56. Aydogan, U.; Durmaz, E.; Ercan, C.M.; Eken, A.; Ulutas, O.K.; Kavuk, S.; Gursel, O.; Alanbay, I.; Akay, C.; Kurekci, A.E.; et al. Effects of smoking during pregnancy on DNA damage and ROS level consequences in maternal and newborns' blood. Arh. Hig. Rada Toksikol. 2013, 64, 35-46. [CrossRef]

57. Rua, E.A.O.; Porto, M.L.; Ramos, J.P.L.; Nogueira, B.V.; Meyrelles, S.S.; Vasquez, E.C.; Pereira, T.M.C. Effects of tobacco smoking during pregnancy on oxidative stress in the umbilical cord and mononuclear blood cells of neonates. J. Biomed. Sci. 2014, 21, 105. [CrossRef]

58. Mottalebnejad, M.; Pouramir, M.; Jenabian, N.; Ranjbar Omrani, M.; Bijani, A.; Yarmand, F. Evaluating the association between passive smoking with total antioxidant capacity and salivary lipid peroxidation levels in 12 to 15 year old adolescents. J. Res. Dent. Sci. 2014, 11, 40-44.

59. Fayol, L.; Gulian, J.M.; Dalmasso, C.; Calaf, R.; Simeoni, U.; Millet, V. Antioxidant status of neonates exposed in utero to tobacco smoke. Biol. Neonate 2005, 87, 121-126. [CrossRef]

60. Kurt, A.; Kurt, A.N.C.; Benzer, D.; Aygün, A.D.; Ustündag, B.; Dogan, Y.; Erel, O. Exposure to Environmental Tobacco Smoke during Pregnancy Restrain the Antioxidant Response of their Neonates. J. Neonatal Biol. 2016, 5, 1. [CrossRef]

61. Pickett, K.E.; Rathouz, P.J.; Kasza, K.; Wakschlag, L.S.; Wright, R. Self-reported smoking, cotinine levels, and patterns of smoking in pregnancy. Paediatr. Perinat. Epidemiol. 2005, 19, 368-376. [CrossRef]

62. Paci, E.; Pigini, D.; Bauleo, L.; Ancona, C.; Forastiere, F.; Tranfo, G. Urinary cotinine concentration and self-reported smoking status in 1075 subjects living in central Italy. Int. J. Environ. Res. Public Health 2018, 15, 804. [CrossRef]

63. Seccareccia, F.; Zuccaro, P.; Pacifici, R.; Meli, P.; Pannozzo, F.; Freeman, K.M.; Santaquilani, A.; Giampaoli, S. Research Group of the MATISS Project. Serum cotinine as a marker of environmental tobacco smoke exposure in epidemiological studies: The experience of the MATISS project. Eur. J. Epidemiol. 2003, 18, 487-492. [CrossRef]

64. Boyd, N.R.; Windsor, R.A.; Perkins, L.L.; Lowe, J.B. Quality of measurement of smoking status by self-report and saliva cotinine among pregnant women. Matern. Child. Health J. 1998, 2, 77-83. [CrossRef]

65. Swamy, G.K.; Reddick, K.L.B.; Brouwer, R.J.N.; Pollak, K.I.; Myers, E.R. Smoking prevalence in early pregnancy: Comparison of self-report and anonymous urine cotinine testing. J. Matern. Fetal Neonatal Med. 2011, 24, 86-90. [CrossRef]

66. Bobb-Semple, A.A.; Williams, A.F.; Boggs, M.E.; Gold, K.J. Prenatal Point-of-Care Tobacco Screening and Clinical Relationships. Ann. Fam. Med. 2018, 16, 507-514. [CrossRef]

67. Ware, J., Jr.; Kosinski, M.; Keller, S.D. A 12-item short-form health survey: Construction of scales and preliminary tests of reliability and validity. Med. Care 1996, 34, 220-233. [CrossRef]

(C) 2019 by the authors. Licensee MDPI, Basel, Switzerland. This article is an open access article distributed under the terms and conditions of the Creative Commons Attribution (CC BY) license (http://creativecommons.org/licenses/by/4.0/). 